\title{
A state-of-art survey on project selection using MCDM techniques
}

\section{Soheil Sadi-Nezhad ${ }^{a^{*}}$}

\begin{tabular}{l}
$\frac{{ }^{a} \text { University of Waterloo, Waterloo, On }}{\text { C H R O N I C L E }}$ \\
\hline Article history: \\
Received: March 5, 2017 \\
Received in revised format: May \\
16, 2017 \\
Accepted: June 11, 2017 \\
Available online: \\
June 11, 2017 \\
\hline Keywords: \\
Project selection \\
TOPSIS \\
AHP \\
ANP \\
VIKOR \\
\hline
\end{tabular}

\section{Introduction}

Project selection is considered as the first essential part of project portfolio management. Project selection is also considered as a process to evaluate each project idea and chooses the one with the biggest priority. Project selection plays an essential role in the entire life cycle of different projects (Wu et al. 2014). The scoring technique is a method where the members of a project selection lists relevant criteria, weighs them based on their relative importance and their priorities and then sums the weighted values (Huang et al., 2008; Ramani et al., 2009; Pirdashti et al., 2009; Bakshi et al., 2012; Adhikary et al., 2015). Project selection often is involved with multiple criteria and it is important to use multiple criteria decision making (MCDM) to find an appropriate assessment. During the past few years, there have been tremendous attempts on using MCDM techniques for project selection. In this paper, we review recent advances on the implementation of MCDM techniques for project selection.

* Corresponding author. 


\section{Multi attributes decision making}

The purpose of multi attribute decision making (MADM) is involved with ranking different alternatives subject to some qualitative criteria such as cost, quality, one time delivery, etc.

\subsection{Analytical hierarchy process}

Analytical hierarchy process (AHP) (Saaty, 1986) is a structured method for analyzing complex decisions, according to mathematics and psychology. Fig. 1 shows a simple AHP implementation for project selection where there are two hierarchy in the process.

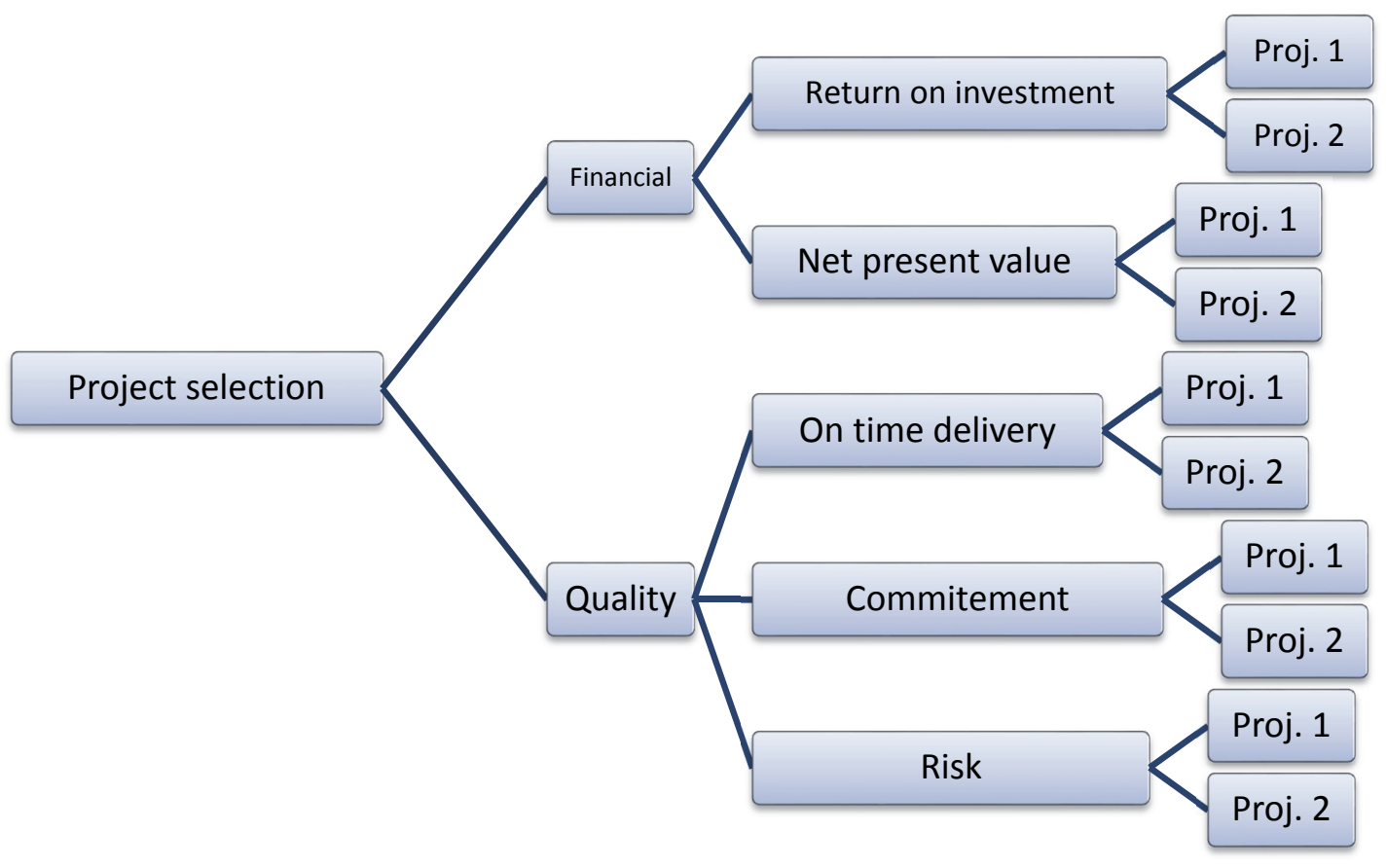

Fig. 1. Analytical hierarchy process

In practice, there are uncertainty (Chen, 2002; Chen \& Cheng, 2009) associated with qualitative pairwise comparisons and data are given in an uncertain form. Öztaysi (2015) used a group decision making approach using interval type-2 fuzzy (Zadeh 1965, 1978, 1996) AHP for project selection. Thipparat and Thaseepetch (2013) presented an integrated VIKOR (Opricovic \& Tzeng, 2004; Bakshi et al., 2011) and fuzzy AHP technique for evaluating a sustainable research project. Alzober and Yaakub (2014) proposed an integrated model for project selection, which consists of two stages. First, it integrates two MCDM methods of AHP and analytical neural network (ANN) to prepare a shortlist of the best alternatives. Next, they applied statistical model COP to select the optimum alternative from the best alternatives in a shortlist. Li et al. (2008) used AHP method with an integration with other MCDM techniques for ranking different alternatives. Yazdani-Chamzini et al. (2013) used AHP method along with other MCDM techniques for selecting the optimal renewable energy.

\subsection{Analytical network process}

The analytic network process (ANP) (Saaty, 1996) is a more general form of the analytic hierarchy process (AHP) where interrelationships among different criteria are also considered. There are literally several applications of ANP for project selection (Chen \& Tzeng, 2010; Liang et al., 2013; Vinodh \& Swarnakar, 2015). Ravi et al. (2008) proposed a hybrid method using ANP and goal programming 
method for selection of a reverse logistics project for end-of-life computers. Wey and Wu (2007) applied ANP priorities with goal programming in resource allocation in transportation. Bai and Zhan (2011) presented a method for an IT Project selection method based on fuzzy ANP. Lee and Kim (2000, 2001) proposed an improved information system project selection methodology which reflect interdependencies among evaluation criteria and candidate projects using ANP within a zero-one goal programming model. Wang et al. $(2012,2013)$ used ANP method for project selection in the presence of other MCDM techniques.

\subsection{The Technique for Order of Preference by Similarity to Ideal Solution}

The Technique for Order of Preference by Similarity to Ideal Solution (TOPSIS) is another MCDM method, which was originally developed by Hwang and Yoon in 1981. The following steps demonstrate the implementation of the TOPSIS method.

Step 1: The quantification and normalization of decision matrix $(N)$ :

To normalize the decision matrix for each element, the following operation is implemented:

$$
n_{i j}=\frac{a_{i j}}{\sqrt{\sum_{i=1}^{m} a_{i j}^{2}}}
$$

Step 2: Obtain the weighted normalized matrix $(V)$ :

To obtain the weighted normalized matrix, the normalized matrix $(\mathrm{N})$ is multiplied by $\mathrm{W}_{\mathrm{n} \times \mathrm{n}}$, which is a square matrix, the diagonal elements are the weights of the indicators and the other elements are 0.

$$
V=N \times W_{n \times n}
$$

Step 3: Obtain a positive ideal $V_{j}^{+}$and a negative ideal $V_{j}^{-}$for each indicator.

Step 4: Determin the distance between each alternative and its positive and negative ideals.

$$
\begin{aligned}
& d_{i}^{+}=\sqrt{\sum_{j=1}^{n}\left(v_{i j}-v_{j}^{+}\right)^{2}} \\
& d_{i}^{-}=\sqrt{\sum_{j=1}^{n}\left(v_{i j}-v_{j}^{-}\right)^{2}}
\end{aligned}
$$

Step 5: Determin the relative proximity of each alternative to the ideal solution.

$$
C L_{i}^{*}=\frac{d_{i}^{-}}{d_{i}^{-}+d_{i}^{+}} \quad C L_{i}^{*}=\frac{d_{i}^{-}}{d_{i}^{-}+d_{i}^{+}}
$$

Step 6: Rank the alternatives:

The alternative with the greater CL is the best alternative to choose.

TOPSIS has been used in various forms for project selection (Dodangeh \& Mojahed, 2009; Opricovic \& Tzeng, 2004). Gao et al. (2008) used Fuzzy TOPSIS algorithm as an MCDM technique with an application in information systems project selection. The work developed a fuzzy technique based on TOPSIS to choose optimal information system in a fuzzy environment where the data are often incomplete. The importance weight of each criterion and the rating of each alternative were explained in linguistic terms and stated in triangular fuzzy numbers. Jafarian et al. (2014) proposed a framework for 
prioritizing and allocating six sigma projects by using fuzzy TOPSIS and fuzzy expert system. Karaveg et al. (2015) proposed an integrate technique using SEM and TOPSIS for the commercialization capability of R \& D project evaluation. Mojahed and Dodangeh (2009) applied engineering economy techniques with group TOPSIS method for project selection management. Baysal et al. (2015) proposed a two phased fuzzy MCDM methodology for project selection in municipality. During the first phase, fuzzy TOPSIS method was implemented to choose the main project group and then fuzzy AHP was applied to choose the best sub-municipal project.

Chang (2013) integrated the ANP and (TOPSIS) to assist Taiwanese managers in century-old food industry firms to make better decisions for new product development (NPD) project selection. Teng et al. (2010) also proposed a systematic budget allocation for transportation construction projects for a case study in Taiwan using MCDM techniques.

Chang (2015) developed a hybrid MCDM model to choose program projects for nonprofit TV stations on the basis of managers' insights. By the concept of balanced scorecard (BSC) (Kaplan \& Norton, 1996) and corporate social responsibility (CSR), they gather essential criteria for choosing the best program project. Fuzzy Delphi method was also implemented to modify criteria. Next, by considering the interdependence among the selection criteria, ANP was also implemented to find the weights of them. To prevent calculation and additional pairwise comparisons of ANP, TOPSIS was finally implemented to rank the alternatives. Dodangeh and Mojahed (2009) considered a real application of project selection for Telecommunication projects by gathering the opinions of experts using TOPSIS method. In their method, they used four types of criteria including qualitative, quantitative, negative and positive criteria for choosing the best one amongst five projects. Perçin and Kahraman (2010) applied a modified Delphi method, AHP and fuzzy TOPSIS (FTOPSIS) methodologies for Six Sigma project selection. In their survey, after the evaluation criteria of Six Sigma projects were completed by Delphi method, the weights of criteria were measured by using the AHP method. The FTOPSIS method was then implemented to reach the final ranking results.

\subsection{VIKOR}

VIKOR, standing for Vlsekriterijumska Optimizacija I Kompromisno Resenje, (Bakshi et al., 2011; Ahmad et al., 2015) method is an MCDM method, which was originally developed by Serafim Opricovic to solve decision problems with conflicting and non-commensurable criteria, assuming that compromise is acceptable for conflict resolution. VIKOR ranks alternatives and detects the solution named compromise which is the closest to the ideal.

VIKOR is used to optimize multi-criteria complex systems by focusing on ranking and choosing set alternatives for a problem with conflicting criteria. The compromise solution is a feasible solution closest to the ideal solution. Compromise, more specifically, is an agreement built by mutual consensus created between different alternatives. Assuming that each alternative is assessed by a criterion function the compromise ranking could be performed by comparing the measure of closeness to the ideal alternative. The value of $L p, j$ states the distance of each alternative from the best ideal solution. The extended VIKOR method applies the following form of $L_{P}$ metric:

$$
L_{p, j}=\left\{\sum_{i=1}^{n}\left[W_{i}\left(f_{i}^{*}-f_{i j}\right) /\left(f_{i}^{*}-f_{i}^{-}\right)\right]^{p}\right\}^{1 / p} \quad 1 \leq p \leq \infty \mathrm{j}=1,2,3 \ldots \mathrm{J}
$$

The compromise ranking algorithm of VIKOR involves the following steps:

a) Determine the best $f_{j}^{*}$ and the worst $f_{j}^{-}$values of all criteria functions $\mathrm{j}=1,2,3 \ldots \mathrm{n}$

$f_{j}^{*}=\max _{i} f_{i j} \quad f_{j}^{-}=\min _{i} f_{i j}$

b) Compute the values of $S_{i}$ and $R_{i}$ as follows, 
$S_{i}=\sum_{i=1}^{n} \frac{w\left(f_{i}^{*}-f_{i j}\right)}{\left(f_{i}^{-}-f_{i j}\right)}$

$R_{i}=\max _{i} \frac{w\left(f_{i}^{*}-f_{i j}\right)}{\left(f_{i}^{-}-f_{i j}\right)}$

where $W i$ is the weight of criteria, expressing their relative importance.

c) Compute the values of $Q_{i}$ :

$$
Q_{i}=\frac{v\left(S_{i}-S^{*}\right)}{S^{-}-S^{*}}+\frac{(1-v)\left(R_{i}-R^{*}\right)}{R^{-}-R^{*}}
$$

where

$$
\begin{array}{ll}
S^{*}=\min _{j} S_{j} \quad, \quad S^{-}=\max _{j} S_{j} \\
R^{*}=\min _{j} R_{j} \quad, \quad R^{-}=\max _{j} R_{j}
\end{array}
$$

Here $v$ is introduced as the weight of the strategy of "the majority of criteria".

d) Rank different alternatives sorting by values of $S, R$ and $Q$ in non-increasing order, Propose as a compromise solution the alternative $\mathrm{A}(1)$, which is the best ranked by the measure $\mathrm{Q}$ (minimum), if the following two conditions hold:

a. Acceptable advantage. $\mathrm{Q}\left(\left(\mathrm{A}^{2}\right)\right) \_\mathrm{Q}\left(\left(\mathrm{A}^{1}\right)\right) \geq \mathrm{DQ}$, where $\mathrm{DQ}=1 . \mathrm{j}-1$ and $\mathrm{A}(2)$ is the alternative with second position in the ranking list by $\mathrm{Q}$

b. Acceptable stability in decision-making. The alternative A (1) has to also be the best ranked by S or and $\mathrm{R}$ This compromise solution is stable within a decision-making process, which could be the strategy of maximum group utility (when $\mathrm{v}>0.5$ is needed), or "by consensus" ( $>0.5)$, or with veto $(\mathrm{v}<0.5)$. If one of the conditions is not satisfied, a set of compromise solutions has to be proposed as follows,

a. Alternative $A(1)$ and $A(2)$ if only condition $b$ is not met, or

b. Alternatives $A(1), A(2) \ldots A(M)$ if the condition is not met. A (M) is determined by the relation $\mathrm{Q}\left(\mathrm{A}^{\mathrm{M}}-\mathrm{A}^{1}\right)<\mathrm{DQ}$ for maximum $\mathrm{M}$ (the positions of these alternatives are "in closeness").

VIKOR method has been extensively used in different classifications of decision making problems (e.g. Mohanty, 1992). Thipparat and Thaseepetch (2013) presented an integrated VIKOR and fuzzy AHP method for assessing a sustainable research project. Ebrahimnejad et al. (2012) proposed a two-phase group decision making approach for construction project selection under a fuzzy environment. In their method, they integrated a modified ANP and an improved VIKOR. In addition, to consider uncertainty and risk, a decision making method was also considered with multiple fuzzy information by a group of experts, and a risk attitude for each expert is taken into consideration linguistically. Salehi (2015) used a hybrid of AHP and VIKOR method for project selection.

\subsection{MOORA}

The multi objective optimization on the basis of ratio analysis (MOORA) method considers both beneficial and non-beneficial criteria for ranking the alternatives from a set of existing options. The procedure of the MOORA method is described by Patel and Maniya (2015) as follows,

Step 1: Create the dimensionless decision matrix. The normalization of the decision matrix is performed by using Eq. 7: 


$$
r_{i j}=\frac{x_{i j}}{\sqrt{\sum_{i=1}^{m} x_{i j}^{2}}} \quad \mathrm{i}=1,2, \ldots, \mathrm{m} ; \mathrm{j}=1,2, \ldots, \mathrm{n}
$$

where, $r_{i j}$ is a dimensionless number in the $[0,1]$ interval representing the normalized performance of $\mathrm{i}^{\text {th }}$ alternative on $\mathrm{j}^{\text {th }}$ criteria.

Step 2: Determine the evaluation value of $i^{\text {th }}$ alternative with in terms of all the criteria using Eq. (8) in which $g$ is the number of criteria to be maximized, $(n-g)$ is the number of criteria to be minimized, $\mathrm{w}_{\mathrm{j}}$ is the compromised weight and $\mathrm{y}_{\mathrm{i}}$ is the assessment value (Patel \& Maniya, 2015).

$$
y_{i}=\sum_{j=1}^{g} w_{j} r_{i j}-\sum_{j=g+1}^{n} w_{j} r_{i j} \quad \mathrm{j}=1,2, \ldots, \mathrm{n}
$$

The higher values of $y_{i}$ mean that the rank is better.

MOORA has been used for project selection in different applications. Yazdani (2015) proposed intuitionistic fuzzy MOORA technique with triangular fuzzy numbers in a group decision making situation. He also used a case of project selection problem to validate the applicability of the method. Mohamed and Ahmed (2012) analyzed project selection by using SDV-MOORA approach.

\subsection{Data envelopment analysis}

Data envelopment analysis (DEA) is a method for measuring the relative efficiency of different units where there are more than one input/output. The method was originally developed by Charnes et al. $(1978,1994)$. There are some applications of DEA method for project selection (Yousefi \& HadiVencheh, 2016).

\subsection{Gray Relational Analysis (GRA)}

The Gray system theory was propsoed by Ju-long Deng (1982). A white system is described when the internal message, such as architecture, operation mechanism, system characteristics and parameters, are known, precisely. On the contrary, if one may not achieve any information and characteristics about the system, then it is considered as a black system. Gray space is thus a system described between the white and black systems (Lu et al., 2008). The gray system theory is used to handle obscure problems discrete data and incomplete data. This theory requires relatively less information with variability in the criteria and generates different and satisfactory output. Just like fuzzy theory, the gray theory is an effective mathematical model for handling uncertain problems (Deng, 1982).

There are literally several applications of GRA for project selection (Morán et al., 2006). Hou (2011) used GRA and TOPSIS method for information technology/information system selection. Zavadskas et al. (2010) considered the application of gray relations methodology for defining the utility of alternatives, and offered a multiple criteria method of Complex Proportional Assessment of alternatives with grey relations for analysis. In this model, the parameters of the alternatives were detected by the grey relational grade and stated in terms of intervals. They also presented a case study for the selection of construction project manager. Their results indicated that the method could be implemented as an effective decision aid in multi-criteria selection.

\section{Conclusion}

Project selection is considered as the first essential part of project portfolio management. Project selection is also considered as a process to evaluate each project idea and choose the one with the biggest priority. This paper has presented a brief survey on the applications of MCDM techniques for project 
selection. The survey has indicated that among many existing MCDM techniques, AHP, ANP and TOPSIS has been the most popular methods (See Fig. 2). In many cases, researchers have considered uncertainty in the form of fuzzy or interval data and proposed more sophisticated method for ranking projects (Abbasianjahromi \& Rajaie, 2012; Daneshvar Rouyendegh \& Erol, 2012; Hashemkhani Zolfani et al., 2015). We hope this survey could shed light into the applications of MCDM techniques for project selections.

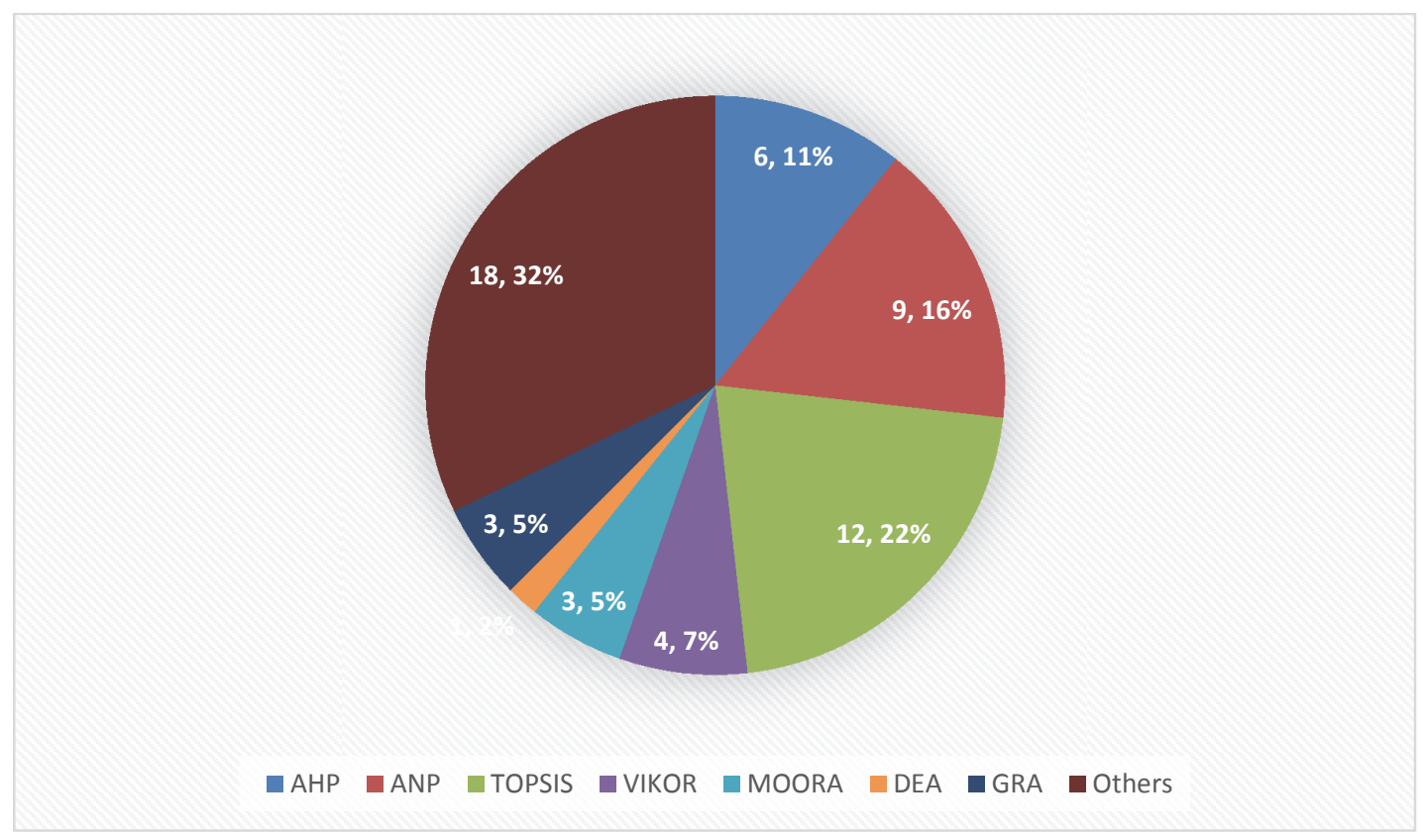

Fig. 2. Distribution of the MCMD applications for project selection

\section{Acknowledgement}

The authors would like to thank the anonymous referees for constructive comments on earlier version of this paper.

\section{References}

Abbasianjahromi, H., \& Rajaie, H. (2012). Developing a project portfolio selection model for contractor firms considering the risk factor. Journal of Civil Engineering and Management, 18(6), 879-889.

Adhikary, P., Roy, P. K., \& Mazumdar, A. (2015). Optimal renewable energy project selection: A multi-criteria optimization technique approach. Global Journal of Pure and Applied Mathematics, 11(5), 3319-3329.

Alzober, W., \& Yaakub, A. R. (2014). Integrated model for MCDM: Selection contractor in Malaysian construction industry. In Applied Mechanics and Materials (Vol. 548, pp. 1587-1595). Trans Tech Publications.

Ahmad, J., Javed, M. K., Nazam, M., \& Nazim, M. (2015). Multiple criteria group decision making problem based on VIKOR method under Hesitant fuzzy environment. In Proceedings of the Ninth International Conference on Management Science and Engineering Management (pp. 1519-1528). Springer Berlin Heidelberg.

Bakshi, T., Sanyal, S. K., Sarkar, B., \& Sinharay, A. (2012, March). A project Selection Framework of DSS by Dempster-shafer Theory under Fuzziness. In Recent Advances in Information Technology (RAIT), 2012 1st International Conference on (pp. 374-378). IEEE. 
Bai, H., \& Zhan, Z. (2011, October). An IT Project selection method based on fuzzy analytic network process. In System Science, Engineering Design and Manufacturing Informatization (ICSEM), 2011 International Conference on (Vol. 2, pp. 275-279). IEEE.

Bakshi, T., Sinharay, A., Sarkar, B., \& Sanyal, S. (2011). MCDM based project selection by F-AHP \& VIKOR. Swarm, Evolutionary, and Memetic Computing, 381-388.

Baysal, M. E., Kaya, İ., Kahraman, C., Sarucan, A., \& Engin, O. (2015). A two phased fuzzy methodology for selection among municipal projects. Technological and Economic Development of Economy, 21(3), 405-422.

Charnes A, Cooper, W. W., Rhodes, E. (1978). Measuring the efficiency of decision making units. European Journal of the Operational Research, 2, 429-44.

Charnes A, Cooper W. W., Lewin, A., Seiford, L. M. (1994). Data envelopment analysis: theory, methodology and applications. Massachusetts: Kluwer Academic Publishers.

Chang, K. L. (2013). Combined MCDM approaches for century-old Taiwanese food firm new product development project selection. British Food Journal, 115(8), 1197-1210.

Chang, K. L. (2015). A hybrid program projects selection model for nonprofit TV stations. Mathematical Problems in Engineering, 2015.

Chen, C. T. (2002). A decision model for information system project selection. In Engineering Management Conference, 2002. IEMC'02. 2002 IEEE International (Vol. 2, pp. 585-589). IEEE.

Chen, C. T., \& Cheng, H. L. (2009). A comprehensive model for selecting information system project under fuzzy environment. International Journal of Project Management, 27(4), 389-399.

Chen, V. Y. C., \& Tzeng, G. H. (2010, July). The best project selection for the environment planning of coastal wetlands region based on a hybrid MCDM model. In Computers and Industrial Engineering (CIE), 2010 40th International Conference on (pp. 1-6). IEEE.

Daneshvar Rouyendegh, B., \& Erol, S. (2012). Selecting the best project using the fuzzy ELECTRE method. Mathematical Problems in Engineering, 2012.

Deng, J. L. (1989). Introduction to grey system theory. The Journal of Grey System, 1(1), 1-24.

Dodangeh, J., \& Mojahed, M. (2009, April). Best project selection by using of Group TOPSIS method. In Computer Science and Information Technology-Spring Conference, 2009. IACSITSC'09. International Association of (pp. 50-53). IEEE.

Ebrahimnejad, S., Mousavi, S. M., Tavakkoli-Moghaddam, R., Hashemi, H., \& Vahdani, B. (2012). A novel two-phase group decision making approach for construction project selection in a fuzzy environment. Applied Mathematical Modelling, 36(9), 4197-4217.

Gao, P., Feng, J., \& Yang, L. (2008, October). Fuzzy TOPSIS algorithm for multiple criteria decision making with an application in information systems project selection. In Wireless Communications, Networking and Mobile Computing, 2008. WiCOM'08. 4th International Conference on (pp. 1-4). IEEE.

Lee, J. W., \& Kim, S. H. (2000). Using analytic network process and goal programming for interdependent information system project selection. Computers \& Operations Research, 27(4), 367-382.

Lee, J. W., \& Kim, S. H. (2001). An integrated approach for interdependent information system project selection. International Journal of Project Management, 19(2), 111-118.

Liang, X., Sun, X., Shu, G., Sun, K., Wang, X., \& Wang, X. (2013). Using the analytic network process (ANP) to determine method of waste energy recovery from engine. Energy Conversion and Management, 66, 304-311.

Li, C. H., Sun, Y. H., \& Du, Y. W. (2008, October). A new MCDM approach based on cross-impact analysis for ranking dependent alternatives. In Wireless Communications, Networking and Mobile Computing, 2008. WiCOM'08. 4th International Conference on (pp. 1-4). IEEE.

Lu, I. J., Lin, S. J., \& Lewis, C. (2008). Grey relation analysis of motor vehicular energy consumption in Taiwan. Energy Policy, 36(7), 2556-2561.

Hashemkhani Zolfani, S., Salimi, J., Maknoon, R., \& Kildiene, S. (2015). Technology foresight about R\&D projects selection; Application of SWARA method at the policy making level. Engineering Economics, 26(5), 571-580. 
Hou, G. (2011, May). IT/IS project selection: A grey multi-criteria decision model approach. In $E$ Business and E-Government (ICEE), 2011 International Conference on (pp. 1-4). IEEE.

Huang, W. C., Teng, J. Y., \& Lin, M. C. (2008, October). Application of fuzzy multiple criteria decision making in the selection of infrastructure projects. In Fuzzy Systems and Knowledge Discovery, 2008. FSKD'08. Fifth International Conference on (Vol. 5, pp. 159-163). IEEE.

Hwang, C.L., \& Yoon, K. (1981). Multiple Attribute Decision Making: Methods and Applications. New York: Springer-Verlag.

Jafarian, A., Nikabadi, M. S., \& Amiri, M. (2014). Framework for prioritizing and allocating six sigma projects using fuzzy TOPSIS and fuzzy expert system. Scientia Iranica. Transaction E, Industrial Engineering, 21(6), 2281.

Kaplan, R. S., \& Norton, D. P. (1996). The balanced scorecard: translating strategy into action. Harvard Business Press.

Karaveg, C., Thawesaengskulthai, N., \& Chandrachai, A. (2015). A combined technique using SEM and TOPSIS for the commercialization capability of R \& D project evaluation. Decision Science Letters, 4(3), 379-396.

Mojahed, M., \& Dodangeh, J. (2009, August). Using engineering economy techniques with group topsis method for best project selection. In Computer Science and Information Technology, 2009. ICCSIT 2009. 2nd IEEE International Conference on (pp. 232-234). IEEE.

Morán, J., Granada, E., Míguez, J. L., \& Porteiro, J. (2006). Use of grey relational analysis to assess and optimize small biomass boilers. Fuel Processing Technology, 87(2), 123-127.

Opricovic, S., \& Tzeng, G. H. (2004). Compromise solution by MCDM methods: A comparative analysis of VIKOR and TOPSIS. European journal of operational research, 156(2), 445-455.

Öztaysi, B. (2015). A group decision making approach using interval type-2 fuzzy AHP for enterprise information systems project selection. Multiple-Valued Logic and Soft Computing, 24(5-6), 475500 .

Mohamed, F., \& Ahmed, A. N. (2012). Analysis of project selection by using SDV-MOORA approach. Life Science Journal, $9(2 \mathrm{~s})$.

Mohanty, R. P. (1992). Project selection by a multiple-criteria decision-making method: an example from a developing country. International Journal of Project Management, 10(1), 31-38.

Patel, J. D., \& Maniya, K. D. (2015). Application of AHP/MOORA method to select wire cut electrical discharge machining process parameter to cut EN31 alloys steel with Brasswire. Materials Today: Proceedings, 2(4), 2496-2503.

Perçin, S., \& Kahraman, C. (2010). An integrated fuzzy multi-criteria decision-making approach for Six Sigma project. International Journal of Computational Intelligence Systems, 3(5), 610-621.

Pirdashti, M., Ghadi, A., Mohammadi, M., \& Shojatalab, G. (2009). Multi-criteria decision-making selection model with application to chemical engineering management decisions. World Academy of Science, Engineering and Technology, 49, 54-59.

Ramani, T. L., Quadrifoglio, L., \& Zietsman, J. (2010). Accounting for nonlinearity in the MCDM approach for a transportation planning application. IEEE Transactions on Engineering Management, 57(4), 702-710.

Ravi, V., Shankar, R., \& Tiwari, M. K. (2008). Selection of a reverse logistics project for end-of-life computers: ANP and goal programing approach. International Journal of Production Research, 46(17), 4849-4870.

Saaty, T. L. (1986). Axiomatic foundation of the analytic hierarchy process. Management science, 32(7), 841-855.

Saaty, T. L. (1996). The analytic network process. Pittsburgh: RWS Publications.

Salehi, K. (2015). A hybrid fuzzy MCDM approach for project selection problem. Decision Science Letters, 4(1), 109-116.

Teng, J. Y., Huang, W. C., \& Lin, M. C. (2010). Systematic budget allocation for transportation construction projects: a case in Taiwan. Transportation, 37(2), 331-361.

Thipparat, T., \& Thaseepetch, T. (2013). An integrated VIKOR and fuzzy AHP method for assessing a sustainable research project. World Applied Sciences Journal, 22(12), 1729-1738. 
Vinodh, S., \& Swarnakar, V. (2015). Lean Six Sigma project selection using hybrid approach based on fuzzy DEMATEL-ANP-TOPSIS. International Journal of Lean Six Sigma, 6(4), 313-338.

Wang, W. M., Lee, A. H., Peng, L. P., \& Wu, Z. L. (2013). An integrated decision making model for district revitalization and regeneration project selection. Decision Support Systems, 54(2), 10921103.

Wang, F. K., Hsu, C. H., \& Tzeng, G. H. (2014). Applying a hybrid MCDM model for six sigma project selection. Mathematical Problems in Engineering, 2014.

Wey, W. M., \& Wu, K. Y. (2007). Using ANP priorities with goal programming in resource allocation in transportation. Mathematical and computer modelling, 46(7), 985-1000.

Wu, Y., Geng, S., Xu, H., \& Zhang, H. (2014). Study of decision framework of wind farm project plan selection under intuitionistic fuzzy set and fuzzy measure environment. Energy Conversion and Management, 87, 274-284.

Yau, Y. (2009). Multi-criteria decision making for urban built heritage conservation: application of the analytic hierarchy process. Journal of Building Appraisal, 4(3), 191-205.

Yazdani-Chamzini, A., Fouladgar, M. M., Zavadskas, E. K., \& Moini, S. H. H. (2013). Selecting the optimal renewable energy using multi criteria decision making. Journal of Business Economics and Management, 14(5), 957-978.

Yazdani, M. (2015). New intuitionistic fuzzy approach with multi-objective optimisation on the basis of ratio analysis method. International Journal of Business and Systems Research, 9(4), 355-374.

Yousefi, A., \& Hadi-Vencheh, A. (2016). Selecting Six Sigma projects: MCDM or DEA?. Journal of Modelling in Management, 11(1), 309-325.

Zavadskas, E. K., Turskis, Z., Tamošaitiené, J., \& Marina, V. (2008). Multicriteria selection of project managers by applying grey criteria. Technological and Economic Development of Economy, 14(4), 462-477.

Zadeh, L. A. (1965). Fuzzy sets. Information and control, 8(3), 338-353.

Zadeh, L. A. (1978). Fuzzy sets as a basis for a theory of possibility. Fuzzy sets and systems, 1(1), 328.

Zadeh, L. A. (1996). Fuzzy logic= computing with words. IEEE transactions on fuzzy systems, 4(2), 103-111.

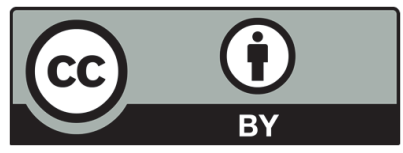

(C) 2017 by the authors; licensee Growing Science, Canada. This is an open access article distributed under the terms and conditions of the Creative Commons Attribution (CC-BY) license (http://creativecommons.org/licenses/by/4.0/). 